\title{
TENDÊNCIAS EVOLUTIVAS DO TURISMO E DA HOTELARIA
}

\author{
Celia Maria de Moraes Dias*
}

\begin{abstract}
RESUMO: Partindo de algumas tendências gerais, examinam-se as perspectivas do turismo e, especialmente da hotelaria, para os próximos anos.
\end{abstract}

UNITERMOS: Hotelaria: perspectivas: tendências. Turismo: perspectivas da hotelaria: tendências.

ABSTRACT: From general tendencies, the study speculates about the fituure of tourism and, specially, of hotel business.

KEYWORDS: Hotel business: perspectives; tendencies. Tourism: hotel busines perspectives; tendencies.

\section{INTRODUÇÃO}

Qualquer previsão, especialmente de longo prazo, é extremamente difícil e tem precisão duvidosa. Por outro lado, muitas coisas podem ocorrer nesta última década, o que pode invalidar a melhor das previsōes. Entretanto, existem algumas tendências que vêm sendo definidas e que podem auxiliar à compreensão do futuro. E são importantes para que se possa analisar as mudanças ambientais e suas implicaçōes, particularmente nas áreas turística e hoteleira.

Segundo o futurólogo norte-americano John Naisbitt (apud Rocherbrune $^{1}$ ) existiram dez megatendências para a próxima década, dentre as quais, as mais fundamentais seriam as seguintes: $o$ abalo da economia mundial; o renascimento das artes; a emergência de um socialismo liberal nos países do Leste; modo de vida universal e particularidades culturais; declínio do Estado-previdência e privatização; impulso da Bacia do Pacífico; tomada do poder pelas mulheres; era da biologia; triunfo do indivíduo. Além disso, o mesmo estudioso reforça que serão importantes as seguintes evoluçōes: de uma sociedade industrial a uma sociedade de informação; de uma tecnologia rígida a uma interativa; de economias nacionais a uma economia mundial; do

(*) Mestre em Ciências da Comunicação pela Escola de Comunicaçōes e Artes da USP. Professora Assistente do Departamento de Relaçōes Públicas. Propaganda e Turismo da ECA/USP.

End. para corresp.: Rua Rui Barbosiı. 914 - 14015 - Ribeirão Preto - SP - Brasil 
curto ao longo prazo; da centralização à descentralização; do assistencialismo à autonomia individual; do poder de ser representado ao poder de participar; das estruturas hierárquicas às estruturas em redes; do norte ao sul; do ou exclusivo às escolhas múltiplas. Peter Drucker, em artigo recente publicado na "The Economist" 2 , lista, também, cinco tendências gerais para os anos 90: a reciprocidade como princípio central de integração econômica internacional; o desenvolvimento de alianças entre empresas para lhes permitir a integração à economia mundial; certa aceleração das reestruturações de empresas; uma retomada em questão da função, responsabilidade e legitimidade do "management"; mudanças políticas numerosas que conferirão primazia aos problemas transnacionais e internacionais.

Como o enunciado dessas megatendências deve vir precedido de estudos, análises conseqüentes e conclusões sobre causas e efeitos dos diversos fenômenos sócio-econômicos, acredita-se que elas sejam examinadas, setorialmente, e verificadas suas implicações sobre cada área, em particular. No que se refere ao turismo e à hotelaria, ao que se sabe, ao menos desde 1980 essa atividade tem sido metódica e constante, tendo em vista, entre outras, as seguintes realizações: o Congresso Internacional da IHA (International Hotels Association), de 1980, teve como tema "A hotelaria no ano 2000"; em 1985, a AIEST (Association Internationale d'Experts Scientifiques en Tourisme) discutiu, num congresso, "Tendências evolutivas da demanda turística"; em 1988, a AMFORT (Associação Mundial para a Formação Profissional Turística) e a ANESTUR (Associação Nacional de Escolas de Turismo da Espanha) realizaram, em Madrid, o seminário internacional "El reto de la industria hotelera en la decada de los noventa", no mesmo ano, a Horwath and Horwath International publica, em Londres, um "report" encomendado pela própria IHA, denominado "Hotels of the Future-Strategies and Action Plan", que busca, segundo as palavras de seu Executive Chairman, J. A. Bodlender, subsidiar seus membros (mais de 300.000 hotéis, em 142 países do mundo) a avaliar suas operações e a planejar, com eficiência, uma estratégia para enfrentar os desafios do século $\mathrm{XXI}^{3}$. O lapso de tempo compreendido pelo estudo refere-se aos próximos 20 a 25 anos. Além desses encontros internacionais, um bom número de pesquisadores têm se dedicado ao estudo e à previsão de tendências futuras para o turismo ${ }^{4.5 .6}$. A partir dessas fontes, cste artigo apresenta as principais tendências que deverão predominar nos próximos anos, na área turístico-hoteleira.

\section{TENDÊNCIAS GERAIS}

Tanto o meio ambiente social como o mundo dos negócios têm sofrido, ultimamente, mudanças em ritmo bastante rápido. Pode-se dividir as tendências em: econômicas (incluindo-se níveis de emprego e um certo crescimento econômico geral que trouxe melhora no nível de vida, infelizmente não equitativamente distribuido a todos os povos e todos os segmentos); sociais (em particular a maior duração das férias remuneradas e, respectivamente, das temporadas de lazer); demográficas (populações mais idosas, mais mulheres participando da força de trabalho); e novas tecnologias que vêm sendo desenvolvidas.

\subsection{Mudanças Demográficas e Sociais}

Um fator-chave que vem influenciando as viagens desde 1936* tem sido as férias remuneradas, cuja duração, entretanto, varia de país para país. A Alemanha e a Holanda têm direito a gozar de sete a oito semanas de férias, anualmente; os Estados Unidos, duas semanas; o Japão recebe as mesmas duas semanas mas, em média, só aproveita oito dias; e a França já conseguiu sua quinta semana de férias pagas. A tendência relativa a períodos de férias mais longos deve resultar em fracionamento das férias, ou seja, férias mais freqüentes, embora com menor duração.

O perfil da população mundial no próximo século será bastante diferente. Em muitos países desenvolvidos tanto o casamento como o nascimento dos filhos têm sido adiados para idades mais maduras, permitindo maiores meios financeiros e tempo para viajar entre os jovens e, particularmente, entre os grupos profissionais. A tendência para redução do tamanho médio das famílias deve continuar. Na Alemanha, a população deve declinar de 4 milhões até o ano 2025.

A população, em muitos países industrializados, está ficando, em média, mais velha, com grandes proporções de cidadãos idosos e alta proporção de pessoas aposentadas, os "grey panthers". A tendência dos denominados "grey panthers" é inversa à que se coloca para o casamento e os filhos; enquanto estes ficam relegados a fases mais tardias ao longo da vida, as pessoas têm começado a trabalhar mais cedo,

(*) Em 20 de junho de 1936. a OIT(Organização Internacional do Trabalho) promulgou uma lei instituindo férias remuneradas e generalizadas com a duração mínima de seis dias úteis. Essa data veio marcar profundamente a história do homem e de sua vida social. A instituição das férias remuneradas tornou-se, mais tarde, o mais poderoso estimulante que o turismo já conheceu ao longo de sua história. (Conforme SEYDOUX. J. De l'hospitalité à l'accucil. Berna. Delta et Spes. 1983. p.92. 
proporção de pessoas aposentadas, os "grey panthers". A tendência dos denominados "grey panthers" é inversa à que se coloca para o casamento e os filhos; enquanto estes ficam relegados a fases mais tardias ao longo da vida, as pessoas têm começado a trabalhar mais cedo, o que, juntamente com algumas novas conquistas sociais - como a diminuição do tempo de trabalho para algumas categorias profissionais tem ocasionado uma diminuição da idade de aposentadoria. Com uma taxa de nascimento decrescente e expectativa de vida aumentada, o Japão está se tornando o país com a população mais velha no mundo. Em 2025, um em cada quatro japoneses terá mais do que 65 anos (hoje, esse número é de um em cada nove). Quanto à população européia, aproximadamente um quarto dela terá mais de 55 anos por volta do ano 2000.

Aposentados e pré-aposentados devem compor uma série de mercados-chave na próxima década. Eles serão, cada vez mais, melhor educados, mais saudáveis e, com freqüência, não possuirão dependentes jovens e nem terão obrigações financeiras. E, dadas suas características, poderão viajar na baixa estação ("off season").

Em anos mais recentes, o número de mulheres na força de trabalho tem crescido substancialmente. No futuro, essa tendência se acentuará e, quanto mais mulheres compuserem a força de trabalho, mais sua importância nos mercados de viagem de negócios crescerá. Mas não será apenas a prosperidade econômica, as mudanças demográficas ou o aumento do tempo livre que influenciarão as tendências de viagens ou a utilização de alojamentos ou restauração no futuro. As conseqüentes mudanças de atitude e valores desempenharão papel vital na decisão de como os consumidores optarão pelo uso de seu tempo de lazer, onde os viajantes de negócios desejarão ficar e que facilidades os hotéis precisarão oferecer para atender às expectativas de seus mercados. Pode-se, particularmente, realçar que a elevação do nível cultural da população mundial gera o desejo de conhecer e descobrir novas localidades, o que, juntamente com as açōes de divulgação dos "mass media" vão estimular a viagem e seus benefícios.

\subsection{Transporte Aéreo}

No caso específico do transporte aéreo, sabe-se que uma das mais notáveis influências para o crescimento rápido da demanda turística tem sido os menores custos do bilhete aéreo e a conveniência e o conforto da viagem que, por sua vez, também influenciam a utilização de hotéis. Sendo assim, acredita-se que os vôos charterizados (fretados totalmente) e a viagem a "forfait", com suas decorrentes reduçōes de preço, devem continuar possibilitando uma maior massificação da atividade que, inicialmente, era privilégio de poucos.

Aliada a esses fatores, a aviação comercial deve expandir suas atividades em razão das novas tecnologias, notadamente no que se refere motores energeticamente mais eficazes. Espera-se, também, que antes do fim do século, já estejam em uso tanto o avião supersônico como o hipersônico.

Por outro lado, algumas áreas, particularmente a Europa e os Estados Unidos, vêm sofrendo problemas crescentes com relação à congestão do espaço aéreo e de seus aeroportos. O problema deve se exacerbar, já que um aeroporto demora dez anos para ser construído e aberto, e há apenas dois em construção atualmente, um em Munich e outro em Denver.

\subsection{Indústria Turística}

Sabe-se que o turismo é uma das maiores indústrias do mundo. As chegadas turísticas mundiais excederam as 300 milhōes de pessoas em 1984, quando o turismo atingiu os US\$100 bilhōes. Dados recentes da Organização Mundial do Turismo mostram que, em 1989, o total de chegadas internacionais atingiu 403 milhōes de pessoas, gerando uma receita de US\$209 bilhōes. As previsōes para o mercado turístico, que cresceu tão rapidamente entre 1960 e 1970, são de que continue crescendo, mas a taxas menores, algo em torno de 4 a $5 \%$ ao ano, até o fim da década. Se essa taxa se confirmar, ter-se-á a duplicação do número de viagens internacionais em menos de 20 anos.

Atualmente, os principais fluxos do tráfego internacional estão altamente concentrados na Europa Ocidental e na América do Norte. $\mathrm{Na}$ Europa, particularmente, pesados fluxos dirigem-se ao perímetro do prazer ("pleasure pheriphery") que engloba os países da Bacia do Mediterrâneo. Esses fluxos do norte para o sul dentro do continente também se refletem na Europa Oriental, com grande volume de turistas voando, no verão, para o Mar Negro. Com o advento da Glasnost e da Perestroika espera-se que os fluxos de viagem atinjam, também os países da Europa Oriental.

Os principais beneficiários da maior dispersão do turismo internacional, recentemente, têm sido os países da Ásia Oriental e da região do Pacífico. Essa tendência deve continuar. A China está se tornando cada vez mais importante como destino, nos últimos anos, e sua política oficial para a indústria hoteleira é que deve tornar-se líder de mercado e competir por turistas estrangeiros com outros destinos internacionais. 
Atualmente, poucos países dominam o mercado como geradores de turistas. Os Estados Unidos e a Alemanha sāo os maiores, juntamente com o Reino Unido gcram um terço das reccitas turísticas internacionais e, junto com o Japāo, França e Canadá geram aproximadamente a metade do total mundial.

\subsection{Crescimento do Mercado e Destinos Futuros}

Acredita-se que o turismo doméstico seja muitas vezes maior do que o internacional, entretanto) isso nāo está tāo bem documentado. O turismo doméstico domina em grandes países como os Estados Unidos e a Índia. Se os viajantes da Comunidade Econômica Européia forem encarados como viajantes domésticos após 1992, o mesmo será verdadeiro para a Europa Ocidental.

Os viajantes de negócios sāo os principais utilizadores de acomodaçōes e serviços hoteleiros. Um segmento importante dentro das viagens de negócios é o público de conferências e congressos. Prevê-se o crescimento das viagens de longa distância, mas a duraçāo média de estada deve cair.

A Ásia Oriental e os países do Pacífico, especialmente o Japāo e os NICS ("Newly Industrialized Countries", ou Países de Industrializaçāo Recente) devem emergir como grandes geradores de turistas. $\mathrm{O}$ mesmo deve ocorrer com os NICS da América Latina.

Novas destinações devem ocorrer, com ênfase em viagens originais, como, aquelas que envolvam atraçōes naturais, como lagos, florestas; áreas com cenário, como parques c reservas naturais; atraçōes sócio-culturais, como festivais, folclore e eventos que divulguem a cultura local; atraçōes feitas pelo homem e mega-atraçōes, como a Disneyworld, A Disncyland ou o Parque Astérix.

\section{INIÚSTRIA HOTELEIRA INTERNACIONAI.}

A denominada indústria hoteleira internacional tom crescido rapidamente nos últimos anos. Foi apenas após a Segunda Guerra Mundial que os negócios tornaram-se internacionais e as cadeias começaram a se estabelecer. De acordo com dados da OMT (Organizaçáo Mundial do Turismo), estima-se a existencia de 1(0,5 milhóes de apartamentos no mundo em hotéis e estabelecimentos similares, dos quais $50 \%$ só na Europa é quase $80 \%$ \%a Europa e EUA juntos.

Segundo seus editores, o "Worldwide Hotel Industry Study", da Howarth and Howarth International, é talve a melhor fonte de dados disponíveis para avaliar o perfil de demanda hoteleira de unidades enre quatro e cinco estrclas ${ }^{3}$ Esse estudo identificou os cinco principais mercados para acomodaçāo hotcleira: viajantes de negócios, turistas (individuais e em grupos), participantes de conferências, funcionários oficiais de governo e outros.

\subsection{Demanda}

Estatísticas do referido estudo indicam que, de 1980 a 1987, o turismo de negócios declinou de 42 para $38 \%$, enquanto o número de participantes de conferência aumentou de 11 para $13 \%$ (os dois segmentos juntos representaram, em 1987, $51 \%$ do mercado total). Mas os padrões variam regionalmente. Enquanto a demanda turística representa $3.3 \%$ na África e Oriente Médio, chega a 55\% na América Latina e Caribe.

O número de hotéis afiliados a cadeias vêm se expandindo (entre 1970 e 1985, o número de apartamentos pertencentes a cadeias cresceu $15 \%$ nas vinte principais cadeias do mundo). Nos Estados Unidos esse volumc é ainda maior; estima-se que, em 1987, por volta de $60 \%$ de seus hotéis fossem pertencentes a cadeias. A estrutura em transformaçāo da indústria hotcleira internacional implica qué os hotéis independentes cada vez mais terāo de se afiliar a uma organizaçāo de marketing ou outra para competir com sucesso.

Tendência de anos recentes tem sido a emergência de relativamente poucas corporações nacionais e internacionais, mas de grande porte - as "megachains". Para o futuro, acredita-se que as marcas líderes hotéis concentrar-se-āo em menos māos, surgindo mais megacadeias, mas podem surgir, também, cadcias novas independentes.

Os hotéis compreendem apenas uma pequena proporçāo do mercado total de acomodaçāo de visitantes. Alguns desses tipos de alojamentos estāo oferecendo competiçāo crescente aos hotêis, particularmente nos mercados de férias. Competiçāo mais acirrada oferecem as "segunda-residência" (tanto as de propriedade total como) as em 
"timesharing"*) - inclusive as adquiridas fora do país de origem**, bem como várias outras formas de acomodação com auto-serviço de alimentaçảo.

\subsection{0 produto-hotel}

Distinguem-se, nitidamente, duas tendências. A primeira refere-se ao fornecimento de serviços incluídos de alta qualidade, bem como diversōes e outras facilidades. A outra busca fornecer valor extra para o dinheiro, reduzindo ou eliminando facilidades extra-apartamento ("non-room") e áreas públicas, tanto quanto possível, o que implica que mais facilidades do tipo faça-você-mesmo serão oferecidas nos apartamentos.

Nos centros de cidades tornar-se-ão populares os apartamentos com serviço de longa estada***. O hotel especializado ("specialist hotel") destina-se a ser o hotel que mais crescerá no futuro. Hotéis de "resort" podem tornar-se parte dos "mega-resorts" com larga utilização de equipamentos de esportes e lazer. Os hotéis de "resort" precisarão oferecer instalaçōes para famílias, de forma a poder competir com as acomodaçōes não-hoteleiras. E aqueles hotéis que estiverem no mercado de convençōes deverão oferecer facilidades de lazer para as esposas ou acompanhantes dos delegados/participantes

O hotel do futuro estará estreitamente alinhado com as evoluçōes da segmentação do produto. Deverão ser observados influências especialmente relativas a:

(*) Timeshare ou multiownership designa, em geral, a aquisição de um alojamento ou o direito de utilização do mesmo durante um período de tempo determinado. geralmente de uma a quatro semanas por ano, durante 25 anos ou por toda a vida. O alojamento pode ser um apartamento, um chalé, hotel ou motel.

(**) Como é o caso dos argentinos, nas praias brasileiras, especialmente do sul; dos norte-americanos, nas ilhas do Caribe e Hawai e, mais recentemente, o caso dos japoneses, com suas fantásticas aquisições no mundo ocidental, como em Paris, New York, Rio de Janeiro.

$\left({ }^{* * *}\right)$ Observa-se essa tendência entre nós, acentuadamente, no caso de São Paulo, na procura por apartamentos com serviços hoteleiros, aqui denominados flat ou residence. a) padrōes demográficos e sociais mutantes - tais como tendência a padrōes crescentes de nível de vida e de aposentadoria - devem ser monitorados de perto pelos hoteleiros, de forma a fornecer o tipo apropriado de produto e serviço e explorar com sucesso novos mercados;

b) o hotel do futuro deve levar em conta as maiores expectativas do mercado em termos de padrōes, de forma a competir com sucesso. Isso pode levar os hoteleiros a uma maior especialização de mercados e operaçōes (procura de nichos particulares);

c) hotéis especializados nos "resorts" terão estaçōes mais longas, já que a demanda crescerá devido a níveis melhores de facilidades, bem como à cficiência de "marketing";

d) o futuro hotel deverá ser melhor desenhado, tanto em termos estéticos, como no que se refere ao conforto para os hóspedes e à eficiência operacional; deverá, ainda, estar em harmonia ambiental com sua comunidade.

Em linhas gerais, o setor HOTOUR (Hotelaria e Turismo) da Organização Internacional do Trabalho, prevê as seguintes tendências para a indústria hoteleira ${ }^{7}$ : regressão dos hotéis de luxo; saturação dos hotéis de três e quatro estrelas; progressão das instalaçōes de duas estrelas; progressão dos hotéis de pequeno e médio porte.

\subsection{Apartamentos Hoteleiros}

O apartamento de hotel deverá ter um melhor "design" e tornarse mais funcional. Em locais apropriados, o quarto terá instalaçōes de um escritório completo, tanto no que se refere ao mobiliário como aos equipamentos. A televisão oferecerá uma grande variedade de funçōes, incluindo "check-out", fornecimento de informaçōes básicas, comunicaçōes tanto internas como externas ao hotel e uma larga gama de diversōes.

Haverá ênfase crescente em sistemas de ventilação e purificação do ar. Também são necessários melhoramentos na iluminação em todos os tipos de hotéis - tanto no quarto quanto no banheiro. Deve continuar a tendência a apartamentos ou setores para não-fumantes. Espera-se, também, melhores facilidades nos apartamentos para as mulheres de negócios. 


\subsection{Restaurante e Cozinha}

Há uma nítida tendência para mais alimentação de lazer ("leisure eating") na maior parte dos países desenvolvidos. Isso implica que os restaurantes tornar-se-ão mais especializados, freqüentementc oferecendo temas especiais e muitos podem procurar nichos de mercado específicos.

A competição crescerá não apenas entre os restaurantes convencionais da vizinhança, mas com os restaurantes de temas específicos, que, freqüentemente, serão comercializados com um "high profile", com lojas que ofereçam alimentos preparados de alta-qualidade ou alimentação caseira.

A "franchising" deverá continuar se expandindo, chegando aos restaurantes de hotel, tanto com o hotel tornando-se o franquiado ou com o restaurante sendo oferecido a um franquiado. Mas, com ou sem "franchise", o restaurante de hotel pode vir a tornar-se um produto de marca.

Avanços tecnológicos tornarão possível, mesmo aos restaurantes relativamente modestos de hotéis, fornecer uma cozinha de alta qualidade. A expectativa é de que se atinja melhores níveis sanitários e de higiene tanto no restaurante como na cozinha.

\subsection{Equipamentos de Esportes, Saúde e Lazer}

Uma tendência nova, mas crescente, refere-se ao fornecimento, pelo hotel, de equipamentos para a prática de esportes, lazer e saúde. Essa tendência deve se acentuar à medida que aumenta a conscientização relativa à importância da prática esportiva e do lazer para a saúde física e mental. Embora, isoladamente, um centro de lazer e saúde ("health center") possa não ser viável financeiramente, sua disponibilidade é freqüentemente necessária para aumentar a ocupação de apartamentos, bem como a utilização de bar/restaurantes. As expectativas do mercado relativas a melhora da qualidade dessas facilidades devem aumentar.

\subsection{Instalações para Eventos}

Salas de conferências deverão ser desenhadas e construídas para atender a esse objetivo, utilizando os melhores equipamentos e tecnologias. Maior atenção deve ser dada ao conforto físico dos delegados.
Serão necessários melhoramentos especialmente nos sistemas de ventilação e purificação de ar. As cadeiras deverão ser ergonomicamente desenhadas, de forma a facilitar a atividade de tomar notas.

\subsection{Animação e Diversões}

Cada vez mais o hotel deixará de ser o local que se procura apenas para dormir e, especialmente nos "resorts", deverá ser desenvolvida a animação. Não a animação-espetáculo, para a observação passiva, mas a animação com participação ativa do hóspede.

Também fora dos hotéis observa-se a tendência à animação participativa, com a popularização dos parques de diversões com museus sociais ou atrações sociais. A Disneywold é um bom exemplo, onde, em setores particulares, as crianças podem participar de certas atividades verificando princípios científicos e suas relações. No Japão, após a extremamente bem sucedida experiência com a montagem da Tokyo Disneyland, existem, atualmente, mais de cem projetos de parques de diversões em estudo. Em abril deste ano, por exemplo, a gigante do setor, Nippon Steel, inaugurou o Space World, local onde os visitantes têm a oportunidade de participar de treinamentos similares aos efetuados na NASA, além de poder observar réplicas de foguetes e ônibus espaciais, como o Discovery.

\subsection{Serviços}

A marca característica do futuro será a qualidade de serviços pessoais que será esperada e que deve ser fornecida. Nos hotéis que se concentram em fornecer um número reduzido de facilidades, com maior nível de auto-serviço dos hóspedes, o serviço pessoal pode e será reduzido, provavelmente com a utilização de avanços tecnológicos para isso. Mas em hotéis que fornecem um alto nível de serviço pessoal, os avanços tecnológicos serão mais equipamentos para melhorar o serviço do que para reduzir o nível de pessoal.

Freqüentemente, a característica de "marketing" mais marcante do hotel independente é a atenção pessoal e a disponibilidade do proprietário, e isso deve continuar.

\subsection{Segmentação do Produto}

A segmentação de produto desenvolveu-se rapidamente em anos recentes, juntamente com outros parâmetros, como preço, nível e fornecimento de facilidades. Algumas empresas hoteleiras oferecem um 
número de produtos diferentes e claramente definidos, por exemplo, a rede Marriott (norte-americana) e o grupo Accor (francês). Accor opera uma escala de diferentes produtos hoteleiros: Sofitel (luxo), Novotel (médio), Ibis (econômico), Urbis (econômico) e Formule 1 (básico). A segmentação de produto deve assumir maior significação no desenvolvimento futuro das empresas hoteleiras, já que é um método efetivo de manter ou expandir seu "market share" e, algumas vezes, criar novos mercados.

As marcas vão se tornar mais focadas e refletirão níveis crescentes de segmentação. Sob esse prisma, o hotel para todos os fins será um "approach" duvidoso em termos de competitividade no mercado. Cada hotel deve reunir um conjunto de produtos particulares e atender a segmentos particulares de mercado, isto é, a grupos de pessoas com características similares e com desejos e necessidades de serviços hoteleiros semelhantes.

Prevê-se dois extremos na segmentação do mercado hoteleiro: os megahotéis - quase cidades dentro de cidades, localizados em arranha-céus e atendendo a uma clientela de negócios; e os pequenos e íntimos inns -que ofereçam um conjunto dos mais luxuosos serviços e confortos pessoais, mas com equipamentos de alta tecnologia ("amenities high tech"), suficientes para satisfazer até ao mais exigente adepto da tecnologia. Em cada extremo e nos níveis intermediários, a introdução de tecnologia sofisticadas irá liberar os "staffs" das tarefas mais rotineiras, de forma que mais tempo qualitativo e serviço atento possam ser devotados aos hóspedes.

Acredita-se que as grandes cadeias hoteleiras, no sentido de conciliar essas duas tendências - e não deixar de atender aos dois tipos de clientes, tenham desenvolvido, há uns dez anos atrás, o conceito de "towers". A idéia é que, num hotel de 1.000 apartamentos, por exemplo, não se consegue dar um atendimento personalizado ao hóspede. Então, separa-se, dentro da estrutura do grande hotel, um andar, uma ala, ou um setor, com apartamentos e suites onde se oferece serviço de um hotel de família sofisticado.

Para os homens de negócios constantemente em viagem - que necessitam de mais serviços dos que os que podem ser colocados e oferecidos num simples apartamento de hotel - foi desenvolvido o centro executivo de negócios ("busines center"), tendência nascente, mas prestes a tornar-se acessório permanente em hotéis que atendam importantes demandas de negócios. Esses centros são equipados com todo o material de escritório e tecnologia mais avançada para atender às necessidades dos executivos, incluindo-se computadores pessoais, "softwares", biblioteca de referência e outros.
Essa tendência à segmentação pode chegar a requintes de sofisticação de atender a necessidades de turistas de negócios em um mercado específico. É o caso do Westin Kowloon Shangri-la, em Hong Kong, que montou um "busines center" com todos os serviços usuais, mais um número de especialidades ajustadas aos costumes e necessidades locais, e utilizando recursos de negócios locais, como: cartōes personalizados em quatro horas, artigos de papelaria personalizados, paginadores, e mesmo assistência nas operaçōes de início de negócios. 8

Na mesma época da criação do conceito de "towers" - por volta de 1980 - a indústria hoteleira começa a conciliar a necessidade de "high tech" (alta tecnologia) com o desejo de high touch (alto toque pessoal) introduzindo o conceito de "all suite", um espetacular golpe de "marketing" que vem se acelerando nos anos 90*. Esse tipo de hotel, de aparência residencial, com suites espaçosas, de muitos quartos, oferecendo preços competitivos frente aos apartamentos "standards" está começando a atender segmentos particulares de viagens. Logo, por exemplo, haverá suites especialmente desenhadas para as necessidades dos viajantes de negócios em grupos, viajantes de negócios de longa estada, famílias em viagens de férias, ou que saem apenas para um fim de semana prolongado.

Prevê-se que os setores com maior possibilidade de crescimento potencial sejam as unidades "all suite" de alta qualidade e os hotéis econômicos, isto é, o limite superior e inferior do mercado. Embora os homens de negócios sejam um segmento próspero e em expansão, estão surgindo outros públicos com necessidades específicas que devem ser atendidas pelo mercado de hospitalidade. Paralelamente às viagens de grupos, organizadas pelas "tour-operators", os clientes individuais, que preparam sua própria viagem, vão se tornando dia-a-dia mais comuns. Surge o turismo verde ou rural, o turismo de aventura, o turismo ecológico e a descoberta de novas rotas e de novos núcleos. Muitos desses turistas compõem-se de jovens, estudantes, ou pessoas de posses mais modestas. Para estes, estão sendo criados os hotéis de uma estrela, por exemplo: na França, o Formule 1 (o pioneiro dessa nova geração, criado em 1985), e outros similares, como Les Balladins, Aster, Nuit d'Hôtel e Premiere Classe. São hotéis que procuram conciliar simplicidade, higiene e conforto a um custo médio bastante baixo (quando foram criados os primeiros, custavam em torno de cem francos, ou US\$10).

(*) Encontram-se. já. em Sảo Paulo. alguns exemplos do "all suite hotel". como o Park Way. do grupo Hojo, na regiāo do Centro Empresarial de São Paulo. 
Também nos Estados Unidos, berço das grandes cadeias e de sofisticados hotéis de luxo, estāo sendo desenvolvidos hotéis econômicos. Pode-se exemplificar com o Sleep Inns, marca que foi desenvolvida pela cadeia Quality International, para atender a clientes de menores posses. Como o público-alvo da cadeia é o norte-americano, uma série de tecnologia foi introduzida para atendê-los mas, ainda assim, são oferecidos apartamentos a baixos custos - variando, em média, entre US\$20 e US\$50.

Em termos gerais, como haverá um leque bastante variado para escolha entre produtos de marca, a competição deve se acirrar e, como conseqüência, desgastar-se-á a lealdade a uma determinada marca.

\subsection{0 "Marketing"}

O "marketing" na indústria hoteleira está em processo de rápida mudança. Evoluções demográficas e sociais estāo causando alterações fundamentais nos mercados, nos perfis de consumidores, regiões e países geradores de turismo.

O produto deve tentar satisfazer expectativas, sonhos e ilusões da demanda. O "marketing” deve criá-las e alimentá-las. O hoteleiro deve conhecer suas oportunidades potenciais de mercado, selecionar aquelas apropriadas ao produto que pode oferecer (com lucratividade), assegurar-se que seu produto é adequado ao seu mercado e, entāo, dirigir seu "marketing" e vendas de acordo e com eficiência de custos.

Os operadores de cadeias têm vantagens óbvias de um setor de "marketing" centralizado, no sentido de que tanto o desenvolvimento da marca como da imagem poderāo se beneficiar com um maior volume de informações de mercado disponíveis, maiores recursos e a possibilidade de atingir um volume maior de clientes. Entretanto, hoteleiros independentes podem obter vantagens comerciais similares às grandes cadeias participando de um consórcio de "marketing."

\subsection{Segurança e Controle Ambiental}

Nos próximos anos os sistemas de cofres convencionais, com chave, não serão mais aceitos pelos hóspedes. O uso do sistema de cartão eletrônico substituirá as chaves convencionais e, logo, haverá integração com cartões de crédito e/ou cartões inteligentes. O cartão de plástico, inevitavelmente, tomará o lugar de muitos documentos, incluindo documentos de viagem e "tickets" aéreos. Com a integração do sistema, um cartão plástico pode ser visto de viagem, "ticket" aéreo, autorização para aluguel de auto, cartão de crédito e chave do apartamento.

Sistemas biométricos para controlar o acesso a áreas de alta segurança nos hotéis tornar-se-āo mais comuns. Esses sistemas podem permitir ou não o acesso através do reconhecimento de características físicas, como a impressão digital ou a retina do olho.

\subsection{Sistemas de Pagamento}

O pagamento à vista deverá continuar em declínio, sendo mais comuns transferências automáticas de fundos. Cobranças imediatas "on line" para todos os bens e serviços consumidos pelo hóspede entrarāo em uso assim que todos os sistemas forem compatibilizados (bancos, cartões de crédito etc.)

\subsection{3 "High-tech and High-touch Concept"}

A indústria hoteleira, particularmente a norte-americana, tem sido bastante afetada pelas mudanças tecnológicas em curso desde a década passada. Hoje, os viajantes esperam que seus hotéis favoritos possuam os mesmos itens (ou maior número deles) que lhes possibilitem desde o conforto pessoal até a eficiência profissional com os quais se acostumaram no lar ou no cscritório. Detectando essa necessidade, os hotéis americanos - das principais cadeias às pequenas e luxuosas pousadas -, estão se estruturando para fornecer novas tecnologias, amenidades, mais espaço e serviços pessoais para manter a ilusāo de um "home away from home" ou de um "office away from the home office". Para isso, estāo implementando tecnologias avançadas e, ao mesmo tempo, procuram não perder o toque pessoal "old-fashioned" ou, como se diz em inglês: "hith-tech and high-touch".

Tome-se como exemplo o hotel Nob Hill Lambourne ${ }^{8}$. Seus criadores procuram dar, aos apartamentos, uma ambientação residencial, semelhante ao lar mas, ao mesmo tempo, equipá-los para qualquer necessidade imaginável de negócios. Eles acreditam: que essa combinação realmente traga de volta o conceito original de hospitalidade "the home away from home"8. Para atender a essa missão, cada um dos 14 apartamentos executivos e 6 suites está decorado, com muito bom gosto, com motivos campestres franceses, realçados por fina mobília, possuem acolchoados de plumas de ganso, obras artísticas originais e uma cozinha completa, com finas porcelanas e toalhas de linho. Mas o elemento distintivo do hotel é a alta tecnologia discretamente integrada à decoração. Cada área de trabalho dos apartamentos possui um equipamento padrāo composto de: escrivaninha, um com 
putador pessoal IBM PS/2 modelo 30-286, com um "hard drive" de 20 "megabytes", pré-carregado com processador de texto ("word proces. sor") e planilha ("spreadsheet"), um aparelho de fax modelo Ricoh 20 "personalize voice mail" e uma linha telefônica direta (que também pode ser respondida pela mesa telefônica, segundo instruções do hóspede). Outros serviços incluem: impressora a laser, fotocopiadoras modernas, "professional desktop publishing", aplicativos de "software" de processadores de texto, serviços de tradução e transcriçāo.

Para enriquecer a experiência do turista em San Francisco, local onde se encontra o hotel, cada computador de apartamento está programado com um guia visual da cidade, com localizaçāo de bancos, centros de diversāo, teatros, boutiques e uma revista dos mais famosos disponíveis restaurantes locais, com exposiçāo dos menus.

Um outro hotel, que estará sendo inaugurado este ano, em Houston, o Marriott Residence Inn, desenhou seus studios (um quarto) e suites (dois quartos) especialmente para atrair hóspedes de longa permanência, que procuram um apartamento para descansar e trabalhar com conforto. A imagem do lar é favorecida pelo uso de dispendiosos ornamentos, como "bay windows" e lareiras reais, já que a lareira, como símbolo do lar, é importante para o hóspede. ${ }^{8}$

Para reforço na criação da ambientaçāo caseira, logo estarão disponíveis, nos hotéis, fornos de micro-ondas, refrigeradores, "compact-discs" e "video-cassette recorders", aparelhos de passar e limpar/lavar roupas, "racks" aquecidos para secar toalhas de banho, tonificadores eletrônicos para o rosto, bem como jatos d'água monitorados eletronicamente na banheira e chuveiro. Prevê-se, para o futuro, que todos os eletrônicos dos apartamentos serāo operados por controles remotos operados a laser.

\section{QUALIDADE DOS SERVIÇOS}

Uma tendência já em vigor atualmente e que deve ser cada vez mais implementada refere-se ao aspecto qualidade nos serviços. Não se espera hoje que uma empresa opere apenas orientada para o lucro Mesmo um esforço massivo de vendas nāo deve mais gerar um alto volume de negócios se as necessidades do consumidor não forem genuinamente atendidas no planejamento, "design" e subseqüente operação do hotel.

Algumas necessidades do hóspede podem ser básicas e físicas, tais como dormir em camas limpas, sentir-se em segurança, ou comer uma refeiçāo completa; outras, tais como a imagem da empresa, o status adquirido pelo fato de fazer certa viagem ou hospedar-se em determinado hotel, de conhecer locais diferentes e relacionar-se com pessoas, são necessidades adquiridas, que vão refletir o que a pessoa busca ser como indivíduo. Para ser bem sucedido, um hotel deve procurar atender a esses dois grupos de necessidades. E, invariavelmente, a manutenção de altos padrões de qualidade vai trazer mais clientes ao hotel ou restaurante. As empresas líderes em qualidade de serviços têm algo em comum: a maior parte de seus negócios é obtida de clientes fiéis.

Para saber o que atrai o viajante pela primeira vez ao hotel e o que o traz de volta, foi conduzida, nos Estados Unidos, recentemente, uma pesquisa. As consideraçōes mais salientes desse estudo foram as seguintes ${ }^{9}$ : mais de dois terços dos respondentes apontaram a relevância dos seguintes fatores:

apartamentos limpos, confortáreis e com boa manutençào:

em localizaçào convenicnte.

- com sen iço rápido e cortês

situados em local seguro; $e$

- com funcionários amigárecis e atenciosos.

Como a limpeza é realmente um dos itens considerados de maior importância para o viajante modemo, tanto a administraçào como todo o staff hoteleiro deve esta completamente envolvida em manter cada elemento da propriedade sem um grào de poeira. Todos os cletalhes de cada aspecto da operaçáo devem ser objeto de atenç̧ão, já qué, embora nào tenha sido apontado um

usualmente o aciimulo de pequenas coisas funcionando mal pode fazer o hospede nào mais retomar

Uma recomendaçào importante da pesquisa é que "embora hóspedes de posses modestas, hospedados em hotíis de classe económica" saibam que estäo pagando por quartos simples. algums poucos extras, sem atmentar substancialmente os custos hoteleiros podem facilmente superar expectativas. A consulta sugere: inclua shampoo

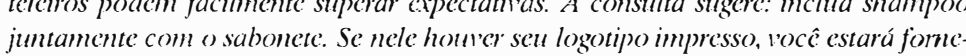
cendo a um hóspede com potcncial de retomo, uma recordaçào de sua empresa. Coloque mais uma toalha de banho. Se rocê já precisou de uma chureirada extra apreciará o valor de uma toalha seca.

Numa pequena àrea contizua ao lobbs principal, pode ser providenciada a instalaçào de um local para senvir café, leite, sucos e päezinhos - que excederäo as expec tativas de todos os hóspedes económicos. Hóspedes adoram "free breakfast". Outras recomendaçoes da pesquisa sào: fomeça um jomal gratuitantintente flores frescas carregain mensagens especiais; garanta que suas "amenities" sejam baseadas em suas próprias características. Proprictários de "resorts" devem estocar loçào bronzeadora: hóspedes na maior parte dos locais apreciam secador de cabelos; e lixas de unhus ou pentes com seu logotipo impresso serào uma contínua lembrança de seu hotel." 
O mais eficiente programa de marketing comeca com a certeza ue que o que ocorre em seu restaurante ou hotel safisfaz seu hóspede atendendo ou superando suas expectativas. Os princípios de satisfação do consumidor são:

1- Reconheça seu hóspede. Como isso nào será possî̀el, especialmente nos grandes hotéis, um sorriso genuíno, um alô caloroso e a interaçáo sincera auxiliam a dar re. conhecimento ao hóspede.

2- Faça uma primeira impressão positiva, já que dificilmente terá uma segunda chance de faze-la. Walt Disnev e Rav Kroc (do Mc Donald's) entenderam bem o significado desse princípio. Muitas vezes pequenos detalhes säo muito importantes para criar uma boa primeira impressào. O maior dos pequenos detalhes é a limpeza.

3- Precncha as espectativas de seus hóspedes. Eles esperam um local que näo thes cause problemas. Nào querem Ier manuais de operą̧ào e nào entendèn nornas e procedimentos da companhia.

4- Reduza o esforço requerido pelo cliente. Os clientes querem fazer o mínimo esforco possivel ao comprar os serviços. O esforço deve vir do lado do produtor, para fa cilitar os atos do consumidor de fazer algum pedido, encontrar um quarto ou receber a conta.

5-Facilite a tomada de decisào do comprador. Como os consumidores nào gostam de tomar decisöes, o fomecedor do seniço deve auxiliá-lo. Pode fazê-lo com venda sugestiva, técnicas de "merchandising" e muita repetiçào das mensagens.

6- Foque sua atençào na percep̧̧ào do cliente. Para ele, percepçào é réalidade. Se ele pensar que você é melhor ou menos barato, você é, independentemente do que o seu menu diz. Para construir um bom relacionamento com os clientes é necessário conhecer o consumidor de uma forma intuitiva, para perceber suas expectativas c percepçòes. Isso nào é fácil, já que o cliente percebe o senvį̧o de fonna idiossincrabica e aparcntemente irracienti ('tno afinna que executw'o de linha acreu. o cliente julga a manutençāo de nossas acronaves pelas gotas de café derramadas sobre a bandeja.

7- Evite violar os limites de tempo näo expressos pelos clientes. O tempo gasto esperando sempre parece quatro vezes mais longo do que é realmente. Imagine como o tempo pode parccer longo a um cliente faminto.

8- Ofereça bons momentos aes clientes, para que se sinta motivado a retomar. Lissa é a base da lealdade do cliente. Se os clientes tiverem boas experiências cm determinado hotel, voltaräo e contarào a outros.

- Espere que os clientes recordem más experiências. As pessoas recordam as más experiencias por mais tempo e com mais detalhes do que as positivas. Eles também contain a mais pessoas suas más experiéncias falgo em torno de cinco ou seis pes-s soas ficam sabendo das ocorências desagradáveis, enquanto contames par apenas uma ou duas pessoas as experiencias positivas).

10- Coloque o consumidor no scu débito. Aprés a venda efentada, o cliente deve sentir que deve ao hotel pela agradavel experiencia e náo que o hotel the deve pelo dinheiro que pagou. Essa sensaçào pode trazer o héspede novamente ao hotet. ${ }^{\text {in }}$

Mas, além dos motivos altruístas de satisfazer aos hóspedes, há um motivo de custo subjacente à premissa que apenas clientes satisfeitos voltam. Simplesmente custa mais conseguir um consumidor do que conservar um. A relação é de dez para um. Para cada US\$10 gastos em publicidade, relaçø̃es públicas, incentivos, descontos e outras promoçōes para conseguir um novo cliente, custa US\$1 para que um cliente antigo retorne. Além disso, a propaganda "boca-a-boca" é grátis. ${ }^{10}$

Concluindo, pode-se dizer que a qualidade é o resultado de um "design" - um projeto de fazer algo diferente dos outros, que o cliente aprecie - e sua implementaçāo, ou seja, fazer da mesma forma, dia após dia. O ponto-chave da implementaçāo será o controle. Se existe controle de qualidade os problemas podem ser identificados e açōes corretivas como treinamento de pessoal, mudanças no "staff" ou nos procedimentos podem ser desenvolvidas. A melhora da qualidade nāo ocorre por acidente. Requer que uma companhia veja em cada contato com um cliente a promessa de um relacionamento de longo prazo. Requer que as decisōes do negócio sejam continuamente assessadas em termos do que o competidor está fazendo. Requer cuidadosa seleção e treinamento de empregados. Requer um comprometimento profundamente arraigado, sustentado através do tempo e implementado por medidas de controle de qualidade. ${ }^{11}$

Aparentemente, o esforço vale considerando-se as evidências demonstradas no estudo sobre gerenciamento de qualidade e reclamaçōes que o TARP (Technical Assistance Research Program) efetuou, em 1984. Nesse estudo, o TARP verificou que: um em cada seis de todos os problemas de qualidade sāo reportados, e nove entre dez compradores desapontados jamais recompram das empresas que os desgostaram ${ }^{11}$. Em outras palavras, de modo geral, os consumidores nāo reclamam, eles apenas nāo voltam mais. A manutençāo de padrōes de qualidade não é, entāo, apenas o caminho para o sucesso. Pode ser uma questāo vital, implicando na sobrevivência ou nāo da empresa.

\section{CONSIDERAÇÕES FINAIS}

Nesse contexto de evoluçāo e de modernizaçāo dos meios de transportes e de diversificaçāo e segmentaçāo dos meios de hospedagem, competindo, cada vez mais agudamente, para atender a uma demanda de clientes cada vez mais exigentes, cabe uma reflexāo: o que o homem procura, hoje, em suas viagens, especialmente de férias?

Apesar de todas as diferenças, culturais, de classe social, de expecativas e ambiçōes pessoais, tanto um viajante alojado num quarto simples de hotel não-classificado, pagando US\$10 o pernoite, quanto 
um turista hospedado numa suite hollywoodiana de US\$1.000/dia desejarão, hoje, como ontem e amanhã, ao fechar a porta de seu quarto, à noite, obter conforto, privacidade e segurança.

Similarmente, os homens, em sua essência, também procuram as mesmas coisas. Etnólogos atestam a existência de mitos em todas as sociedades conhecidas, das menos evoluídas tecnologicamente até as civilizaçōes mais complexas e avançadas. Embora possam nâo se manifestar no dia-a-dia, tão cheio de responsabilidade, horários e compromissos, eles se expressariam, com maior liberdade, durante o período de férias. Segundo Dufour, o turista, em suas férias procurará viver uma série de mitos, os mesmos que estimularam nossos ancestrais, que se pode resumir como segue.

Ele pensa recncontrar os bons velhos tempos no retomo à natureza (o mito da Idade do Ouro): uma naturcza huaruriante, numa sociedade de abundância (o mito do Comucópia, da abundância). Stua sede de juecntude (o mito da Fonte da Ju'entude) é temperada com o desequilíbrio ccologico, que o faz temer as catástrofes (o mito do Deserto). Mas esse homem evoluído guarda zonas infantis. E procura sua mäe tanto nas entranhas das vilas e cidades (o mito de Heliópolis), como nos clenentos da naturcza (o mito de Édipo). Ele é atraído tanto pelas alturas (o mito do Olimpo), como pelas ágras (o mito de Posseidon): cle se dedica a toda sorte de jogos to mito de Olímpia), particulannente os jogos de azar (o mito da Forruna). As férias sào a época ideal para idolatrar seu corpo (o mito de Afrodite), para praticar o encontro amoroso (o mito de Eros), para festejar (o mito de Baco) e para manifestar seu $\mathrm{cu}$ nas artes e na cultura (o mito de Mincri'a), a bricolagem-astaicia, engano - (o mito de Prometcu) ou a viagem (o mito de Ulisses). O sentido de sagrado fá-lo viver uma religiào (o mito de Zeus) ou seus sucedâneos, como a superstição ou a magia (o mito do Feiticeiro/Bnuxo). Certas pessoas näo conseguem jamais liberar uma tempo para o lazer (o mito de Sisifo); outras conscgucm, mas para encontrar a desgraça, a infelicidade (o mito de Pandora). No fundo, nào há senào um mito essencial com vinte facetas: durante o tempo de férias, o homem quer sair da terra maldita, do trabalho repetitivo e da selva urbana para viver uma vida bucólica no paraíso reencontrado, a terra sem mal. ${ }^{\text {I' }}$

E, quando distante de seu lar, o viajante desejará ser "the guest", cuja melhor tradução, nesse caso, não é apenas o hóspede, mas sim o convidado, que espera de seu "host" (hospedeiro) todas as honras que julga merecer.

\section{REFERÊNCIAS BIBLIOGRÁFICASS}

1. ROCHEBRUNE. Renaud de. Les Amneés 90 - Editorial. Revue Française de Gestion. Paris. Fondation Nationale pour l'Fnseignement de la Gestion de Entreprises. (77): 1-2. jan./fev. 1990. p.2.

2. The Economist. 21/10/89. Apud: ROC.HF:BRUNF., ibid. p.2
3. HOTELLS of the future: stratevies and action plan. London, International Hotel Association. 1988. (Summary of report by Horwath and Hotwath)

4. KIBEDI. George. Future trends in international tourism. Reme de Tourisme. Berne. SaintGall. All:ST. 36(1):3-6, jan./mar. 1981

5. PUDDU. Giuseppe Loy. Les ressources humaines dans le décloppenent touristique du XXIe. siecle. Revue de Tourisme. Saint-Gall. AII:ST. 44(1):7-9. jan./mar. 1989

6. FIGUEROLA PAI OMO. Manoel. El futuro del turismo internacional. Esardios Turísticos. Madrid. Instituto Espanol de Turismo. (81):29-43. prim. 1984.

7. PUDDU. Giuseppe I oy. Fi hombre como eje del desatio de la hotelaria en los años 90. Cuadernos de AMFORT. Madrid. AMFORT. s.n.. jun. 1988. p. 31.

8. BERNARD. Joe, Homey, high-tech hotels. TWA-Ambassador. Miami, Halsey Publishing. jun. 1990, p. 16-22.

9. KNUTSON. Bonnic. Freguent travellers: making them happy and bringing them back. The Comell Hotel and Restaurant Administration Quarterly: New York, School of Hotel Administration. 29(1):83-7 May 1988, p.84.

10. KNUTSON. Bonnie. Ten laws of customer satistaction. The Comell Hotel and Restaurant Administration Quarterh: New York. School of Hotcl Administration, 29(3):14-7. Nov. 1988, p.14-7.

11. DeSOUZA. Glenn. Now service business must manage quality. The Joumal of Business Strategr: Boston. Warren. Gorham and Lamont. 10(3):21-5, May/Jun. 1989. p. 23 .

12. DUFOUR, apud SEYDOUX. J. De Thospitalité à l'accucil. Berna. Delta et Spes. 1983, p.7. 